UCRL-ID-130502

\title{
Summary of Model to Account for Inhibition of CAM Corrosion by Porous Ceramic Coating
}

\author{
Robert Hopper \\ Joseph Farmer \\ Keith Wilfinger
}

March 31, 1998

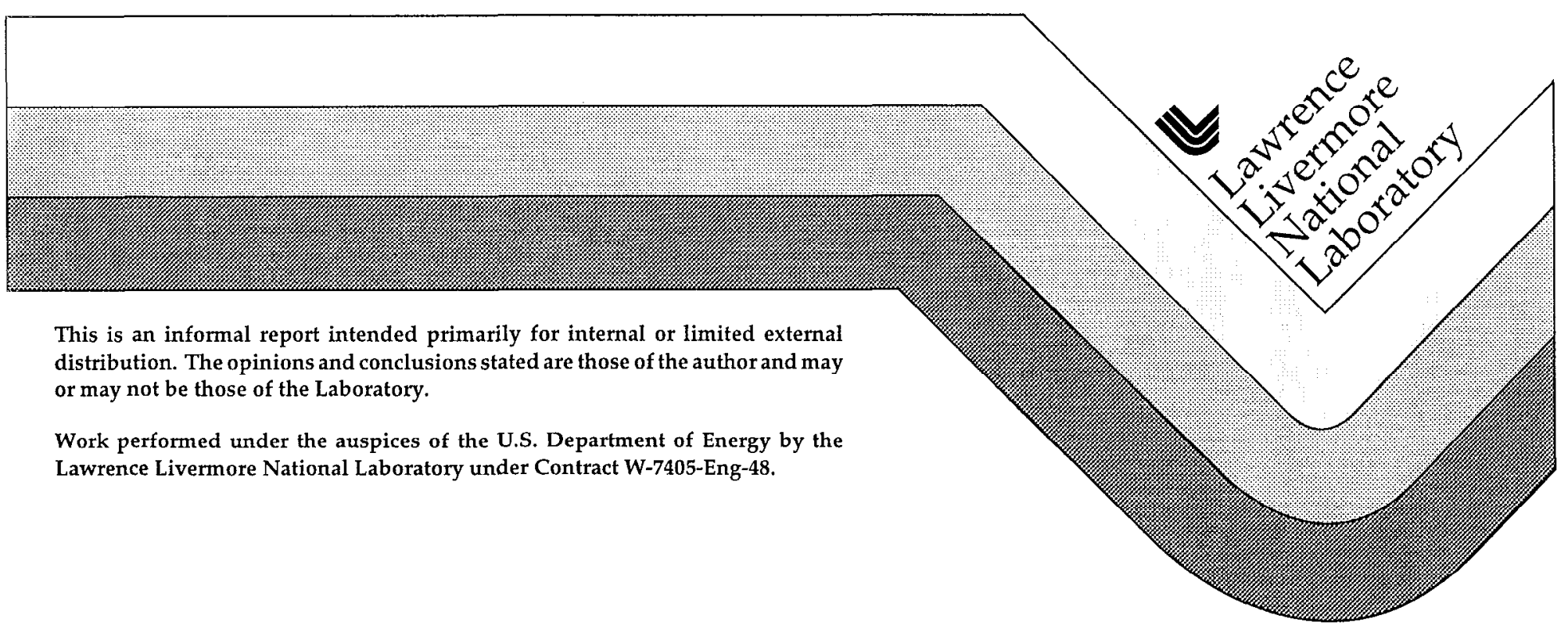




\section{DISCLAIMER}

This document was prepared as an account of work sponsored by an agency of the United States Government. Neither the United States Government nor the University of California nor any of their employees, makes any warranty, express or implied, or assumes any legal liability or responsibility for the accuracy, completeness, or usefulness of any information, apparatus, product, or process disclosed, or represents that its use would not infringe privately owned rights. Reference herein to any specific commercial product, process, or service by trade name, trademark, manufacturer, or otherwise, does not necessarily constitute or imply its endorsement, recommendation, or favoring by the United States Government or the University of California. The views and opinions of authors expressed herein do not necessarily state or reflect those of the United States Government or the University of California, and shall not be used for advertising or product endorsement purposes.

This report has been reproduced directly from the best available copy.

Available to DOE and DOE contractors from the Office of Scientific and Technical Information

P.O. Box 62, Oak Ridge, TN 37831

Prices available from (615) 576-8401, FTS 626-8401

Available to the public from the

National Technical Information Service

U.S. Department of Commerce

5285 Port Royal Rd.,

Springfield, VA 22161 


\title{
Summary of Model to Account for Inhibition of CAM Corrosion by Porous Ceramic Coating
}

\author{
Robert Hopper, Joseph Farmer \& Keith Wilfinger \\ University of California, Lawrence Livermore National Laboratory \\ 7000 East Avenue or P.O. Box 808 \\ Livermore, California 94550
}

Corrosion occurs during five characteristic periods or regimes. These are summarized below. For more detailed discussion, see the attached Memorandum by Robert Hopper entitled "Ceramic Barrier Performance Model, Version 1.0, Description of Initial PA Input" and dated March 30, 1998.

Regime I: Initial period of dry oxidation. The impedance to gas-phase mass transport is relatively insignificant. A good approximation is to simply apply the dry oxidation rate provided by Henshall [Numerical Predictions of Dry Oxidation of Iron and Low-Carbon Steel at Moderately Elevated Temperatures, UCRL-JC-124639, November 1996]:

$$
\begin{aligned}
& x_{o x}(t)^{2}=x_{o x}\left(t_{0}\right)^{2}+2 k_{p} \int_{0} \exp [-Q / R T(t)] d t \\
& k_{p}=4.3 \times 10^{-5} \frac{\mathrm{cm}^{2}}{\mathrm{~s}} \\
& Q=104 \frac{\mathrm{kJ}}{\mathrm{mol}} \\
& R=8.314 \frac{\mathrm{J}}{\mathrm{mol}} \\
& \beta=0.48
\end{aligned}
$$

Note that this expression predicts an oxide thickness of approximately $6.24 \mu \mathrm{m}$ after 1000 years of dry oxidation at a fixed temperature of $150^{\circ} \mathrm{C}$.

Regime IIa. Pores partially filled with moisture. During this period, the corrosion rate is assumed to be limited solely by oxygen transport through gas-filled pores. Impedance of the corrosion rate by the oxide formed at the air-CAM interface during Regime I is ignored. In this specific case, the estimated corrosion rate is unrealistically high. Though this hypothetical scenario (regime) was considered, we do not believe that it has any relevance to actual WP performance and TSPA-VA.

Regime IIb. Pores partially filled with moisture. The corrosion rate is assumed to be limited by the corrosion layer formed at the air-CAM interface (located at the base of pores). Typical humid air corrosion (HAC) rates apply $(60 \%<\mathrm{RH}<80 \%$ \& no dripping condition). The gasfilled pores do not significantly impede the rate of HAC. Assuming a penetration rate of only 10 $\mu \mathrm{m} / \mathrm{y}$, it will take several thousand years to reach the fracture strain. The system should transition to Regime III-VI $(80 \%<$ RH \& dripping condition) long before fracture occurs. 
Regime III-VI. Pores completely filled with moisture. Typical aqueous phase corrosion rates apply at the ceramic-CAM interface $(80 \%<\mathrm{RH} \&$ dripping condition). In this case, development of an appropriate model begins with consideration of the flux of oxygen, $\mathrm{N}_{\mathrm{A}}$, through multiple diffusion barriers, represented by subscripts P and Q (phases P and Q).

$$
N_{A}=k_{P}\left(a_{P B}-a_{P i}\right)=k_{Q}\left(a_{Q i}-a_{Q B}\right)=k_{a}\left(a_{P B}-a_{Q B}\right)
$$

The overall mass transfer coefficient (mass transfer resistance) can be expressed in terms of the individual mass transfer coefficients for phases P and Q [T. K. Sherwood, P. L. Pigford, C. R. Wilkc, Mass Transfcr, McGraw-Hill, San Francisco, 1975, pp. 178-182].

$$
\frac{1}{K_{A}}=\frac{1}{k_{P}}+\frac{1}{k_{Q}}
$$

Pores are treated as long cylinders of length $\delta$.

$$
N_{A}=\frac{D_{A}}{\delta}\left(a_{P B}-a_{P i}\right)
$$

The average flux of oxygen per unit area of waste package is then:

$$
\overline{N_{A}}=\frac{\theta}{\delta} D_{A}\left(a_{P B}-a_{P i}\right)
$$

where $\theta$ is the fraction of the CAM exposed to the aqueous phase at the ceramic-CAM interface. This can be interpreted as porosity. Values of 0.02-0.03 have been achieved with HVOF. The overall mass transfer coefficient is then:

$$
\begin{aligned}
& \frac{1}{K}=\frac{1}{k_{0}}+\frac{1}{k_{I}}=\frac{1}{k_{0}}+\frac{\delta}{\theta D_{A}} \\
& K=\frac{1}{\frac{1}{k_{0}}+\frac{\delta}{\theta D_{A}}}
\end{aligned}
$$

The factor used to correct the oxygen-limited corrosion rate for the presence of a porous ceramic barrier is then:

$$
g=\frac{\overline{N_{A}}}{\overline{N_{A, 0}}}=\frac{\frac{1}{k_{0}}}{\frac{1}{k_{0}}+\frac{\delta}{\theta D_{A}}}=\frac{1}{1+\frac{k_{0} \delta}{\theta D_{A}}}
$$


Note that this correction factor assumes simple cylindrical pores, which is very unrealistic. Actually, the pores in ceramic coatings can be better represented by an array of chains, each link being composed of a hollow sphere and a relatively narrow hollow cylinder, connected in series. In such a case, the analysis of porosity described in the attachment by Hopper should be used. Specifically, the mass transfer coefficient for the ceramic coating, $\mathrm{k}_{\mathrm{I}}$, should be reduced by a factor $f(\varepsilon, \lambda)$ :

$k_{l, \text { corrected }}=f(\varepsilon, \lambda) \times k_{I}$

where $f(\varepsilon, \lambda)$ is defined as:

$f(\varepsilon, \lambda)=\frac{3}{2} \frac{(1+\lambda)^{2}}{\lambda} \varepsilon^{2}$

Here the dimensionless parameters $\varepsilon$ and $\lambda$ represent the geometry of the sphere-cylinder chain:

$\varepsilon=\frac{\text { diameter of cylinder in chain }}{\text { diameter of sphere in chain }}$

$\lambda=\frac{\text { length of cylinder in chain }}{\text { diameter of sphere in chain }}$

Reasonable estimates for $\varepsilon$ based on actual microstructures are as follows:

$\varepsilon=0.05 \quad$ (upper limit, worst case)

$\varepsilon=0.03 \quad$ (good guess)

$\varepsilon=0.01 \quad$ (good guess)

Reasonable estimates for $\lambda$ based on actual microstructures are as follows:

$\lambda=5 \quad$ (minimum)

$\lambda=10 \quad$ (best guess)

$\lambda=30 \quad$ (maximum)

The following estimate of $f(\varepsilon, \lambda)$ is therefore considered reasonable:

$f(0.03,10)=0.016$

$f(0.05,10)=0.045$ 
As an average for now, we estimate $f(\varepsilon, \lambda)$ to be approximately 0.03 , which is mid range. Given this model for the interconnected porosity in the ceramic coating, the modified factor used to correct the oxygen-limited corrosion rate for the presence of a porous ceramic barrier is then:

$$
g_{\text {corrected }}=\frac{1}{1+\left(\frac{k_{0} \delta}{\theta D_{A}}\right)\left(\frac{1}{f(\varepsilon, \lambda)}\right)}
$$

The following stoichiometry is assumed to exist between iron and oxygen:

$4 \mathrm{Fe}+3 \mathrm{O}_{2} \longrightarrow 2 \mathrm{Fe}_{2} \mathrm{O}_{3}$

The relationship between the oxygen flux in a single pore, $\mathrm{N}_{\mathrm{A}}$, and the corrosion rate, $\mathrm{dp} / \mathrm{dt}$, can be written as:

$3 N_{A, 0}=3 k_{0}\left(C_{\text {oxygen }}\right)=4 \frac{\rho}{w} \frac{d p}{d t}$

where $\mathrm{w}$ is the atomic weight of iron:

$$
w=55.847 \mathrm{~g} \mathrm{~mol}^{-1}
$$

and where $\rho$ is the density of iron:

$$
\rho=7.86 \mathrm{~g} \mathrm{~cm}^{-3}
$$

A very conservative value of the aqueous phase corrosion rate is assumed as a basis for calculating the apparent mass transfer coefficient representing corrosion in the absence of a porous ceramic barrier.

$$
\frac{d p}{d t} \approx 300 \frac{\mu m}{y}=\frac{300 \times 10^{-4}}{365 \times 24 \times 3600} \frac{\mathrm{cm}}{\mathrm{s}}=9.513 \times 10^{-10} \frac{\mathrm{cm}}{\mathrm{s}}
$$

This corrosion rate is 6-month data from the Long Term Corrosion Test Facility (LTCTF) at LLNL and is documented by Farmer [J. C. Farmer, "Development of Corrosion Models for High-Level Waste Containers," Proceedings of the $6^{\text {th }}$ International Conference on Nuclear Engineering, ICONE-6, May 10-15, 1998, ASME, 1998, 13 p.]. The concentration of oxygen dissolved in water (equilibrium with ambient air) at the air-ceramic interface is:

$$
C_{\text {oxygen }}=2.56 \times 10^{-7} \frac{\mathrm{mol}}{\mathrm{cm}^{3}}
$$


This solubility is lowered with the addition of salt. This value can be found in Farmer's input to the Expert Elicitation Panel [J. C. Farmer, Table 13 in "Waste Package Degradation Expert Elicitation Panel: Input on the Corrosion of CRM Alloy C-22," Rev. 7, Geomatrix, San Francisco, CA, March 14, 1998, 30 p.].

The flux of oxygen associated with this mass transfer coefficient is then:

$$
N_{A, 0}=\left(\frac{4}{3}\right) \frac{7.86 \times 9.513 \times 10^{-10}}{55.847} \frac{\mathrm{mol}}{\mathrm{cm}^{2} \mathrm{~s}}=\left(\frac{4}{3}\right) 1.339 \times 10^{-10} \frac{\mathrm{mol}}{\mathrm{cm}^{2} \mathrm{~s}}=1.790 \times 10^{-10} \frac{\mathrm{mol}}{\mathrm{cm}^{2} \mathrm{~s}}
$$

The mass transfer coefficient in the absence of a ceramic barrier is then estimated as:

$$
\begin{aligned}
& k_{0}=\frac{1}{C_{\text {oxygen }}}\left(\frac{4}{3}\right) \frac{\rho}{w} \frac{d p}{d t} \\
& k_{0}=\frac{1.785 \times 10^{-10}}{2.56 \times 10^{-7}} \frac{\frac{\mathrm{mol}}{\mathrm{cm}^{2} \mathrm{~s}}}{\frac{\mathrm{mol}}{\mathrm{cm}^{3}}}=6.973 \times 10^{-4} \frac{\mathrm{cm}}{\mathrm{s}}
\end{aligned}
$$

The factor needed for correction of the corrosion rate for the presence of a porous ceramic coating is then:

$$
g_{\text {corrected }}=\frac{1}{1+\frac{(0.15 \mathrm{~cm})\left(6.973 \times 10^{-4} \frac{\mathrm{cm}}{\mathrm{s}}\right)}{(0.02)\left(10^{-5} \frac{\mathrm{cm}^{2}}{\mathrm{~s}}\right)(0.03)}}=5.736 \times 10^{-5}
$$

Therefore, the porous ceramic coating would lower the aqueous phase corrosion rate from approximately $300 \mu \mathrm{m} / \mathrm{y}$ to only $8.602 \times 10^{-2} \mu \mathrm{m} / \mathrm{y}$.

$$
\frac{d p}{d t}=g_{\text {correcled }}\left(\frac{d p}{d t}\right)_{0}=1.721 \times 10^{-2} \frac{\mu m}{y}
$$

An estimate of the time to fracture due to the formation of corrosion products at the ceramicCAM interface can be estimated, provided that the mechanical properties of the ceramic are known. Estimated propertics for the ccramic coating are taken from a text on engineering materials and are summarized in Table I [P.A. Thornton, V. J. Colangelo, Fundamentals of Engineering Materials, Prentice Hall, Englewood Cliffs, NJ, 07632, 1985]: 
Table I. Mechanical Properties of Ceramic Coatings

\begin{tabular}{|l|l|l|l|l|}
\hline Property & $\begin{array}{l}\text { Elastic } \\
\text { Modulus (E) }\end{array}$ & $\begin{array}{l}\text { Elastic } \\
\text { Modulus }(E)\end{array}$ & $\begin{array}{l}\text { Fracture } \\
\text { Strength }\left(\sigma^{*}\right)\end{array}$ & $\begin{array}{l}\text { Fracture } \\
\text { Strength }\left(\sigma^{*}\right)\end{array}$ \\
\hline Units & $\mathrm{MPa}$ & Mpsi & Mpa & Ksi \\
\hline $\mathrm{Al}_{2} \mathrm{O}_{3}$ & 365,000 & 53 & 172 & 25 \\
\hline $\mathrm{ZrO}_{2}$ & 144,900 & 21 & 55 & 8 \\
\hline
\end{tabular}

The range of fracture toughness values observed for typical ceramics is given as:

$$
K_{I C}=3.3 \text { to } 5.8 \mathrm{MPa} \sqrt{m}=3.0 \text { to } 5.3 \mathrm{ksi} \sqrt{\mathrm{in}}
$$

While these properties serve as a good starting place for TSPA-VA, handbook values for mechanical properties of ceramics will probably need to be revised to better reflect those of actual coatings. Direct measurement of the elastic modulus is required.

The rate of expansion of the inner radius of the ceramic barrier coating is estimated from the penetration rate, accounting for the expansion at the interface due to the density difference between $\mathrm{Fe}_{2} \mathrm{O}_{3}$ and $\mathrm{Fe}$ :

$$
\frac{d R}{d t}=2 \frac{d p}{d t}=2 \times 1.721 \times 10^{-2} \frac{\mu m}{y}=3.442 \times 10^{2} \frac{\mu m}{y}=3.442 \times 10^{-8} \frac{m}{y}
$$

Given the inner radius,

$$
R=1 m
$$

the strain rate in the ceramic coating can be estimated:

$$
\frac{d e}{d t}=\frac{1}{2 \pi R} 2 \pi \frac{d R}{d t}=3.442 \times 10^{-8} \frac{1}{y}
$$

The relationship between the stress and strain must be noted:

$$
\sigma=E \times e
$$

The fracture strain can then be estimated from the elastic modulus and the fracture stress.

$$
e^{*}=\frac{\sigma^{*}}{E}=\frac{172 \mathrm{MPa}}{356,000 \mathrm{MPa}}=4.831 \times 10^{-4}
$$

The time required for the strain to reach the fracture strain determines the time to fracture. This is the time required for formation of the first crack in the ceramic coating, but does not necessarily imply failure of the coating. 
$\tau^{*}=\frac{e^{*}}{d e / d t}=\frac{4.831 \times 10^{-4}}{3.442 \times 10^{-8}} y=14,037 y$

The critical flaw size for crack initiation is estimated as:

$$
a^{*} \approx\left(\frac{K_{I C}}{\sigma^{*}}\right)^{2} \frac{1}{\pi}=\left(\frac{3.3 M P a \sqrt{m}}{172 M P a}\right)^{2} \frac{1}{\pi}=1.172 \times 10^{-4} \mathrm{~m}=117.2 \mu \mathrm{m}
$$

where the fracture toughness is defined as:

$$
K_{I C}=\sigma \sqrt{\pi a} f(a, W)
$$

Regime V. Corrosion due to carbon excessive carbon dioxide in gas phase; considered unlikely.

Summary - Regimes I-V. The existence of a slightly porous ceramic coating on the surface will significantly lengthen the life of the container, adding an estimated minimum of 14,037 years to the life of the waste package (Table II). It is more likely that several thousand more years would be added. Additional life can be added by taking steps to close interconnected porosity in the porous ceramic coating. For example, the surface could be coated with $\mathrm{Zn}$ - or Al-based coatings, which would oxidize, thereby filling the pores with the corresponding metal oxides. Both $\mathrm{Zn}$ and $\mathrm{Al}$ are attractive candidates for filling closing porosity since they would be sacrificial to the A516 Gr 55 in possible galvanic couples. The modified g-factor presented here can be used as a practical means to adjust CAM corrosion rates to account for the ceramic coating.

Table II. Extension of WP Life with Ceramic Coating

\begin{tabular}{|l|l|l|}
\hline & $\begin{array}{l}\text { Life with } \\
\text { Ceramic Coating (y) }\end{array}$ & $\begin{array}{l}\text { Life without } \\
\text { Ceramic Coating (y) }\end{array}$ \\
\hline Thermal Pulse & $\sim 1000$ & $\sim 1000 \mathrm{y}$ \\
\hline Ceramic Barrier & $>14,037$ & $\sim 0$ \\
\hline CAM - After Exfoliation & $>333$ & $>333$ \\
\hline
\end{tabular}

Work is in progress at LLNL to verify the corrected g-factor through application of ac impedance spectroscopy. This technique has been applied to a variety of other practical problems over the past 15 years by one of the authors [J. C. Farmer, "Underpotential Deposition of Copper on Gold and the Effects of Thiourea Studied by AC Impedance," Journal of the Electrochemical Society, Vol. 132, No. 11, pp. 2640-2648, 1985]. A P $\Lambda$ R Model 273 with either a Solaritron frequency response analyzer or a dual-channel lock-in amplifier will be used to determine the complex impedance of the electrolyte-filled ceramic barrier over the frequency range extending from $0.001 \mathrm{~Hz}$ to $500 \mathrm{kHz}$. With a well planned experiment and proper interpretation of the data, insight into transport in the pores should be possible. It should also be possible to develop some understanding of the layer of corrosion products at the base of the pores. Note that dc measurements have already been done by Wilfinger et al. with success. 


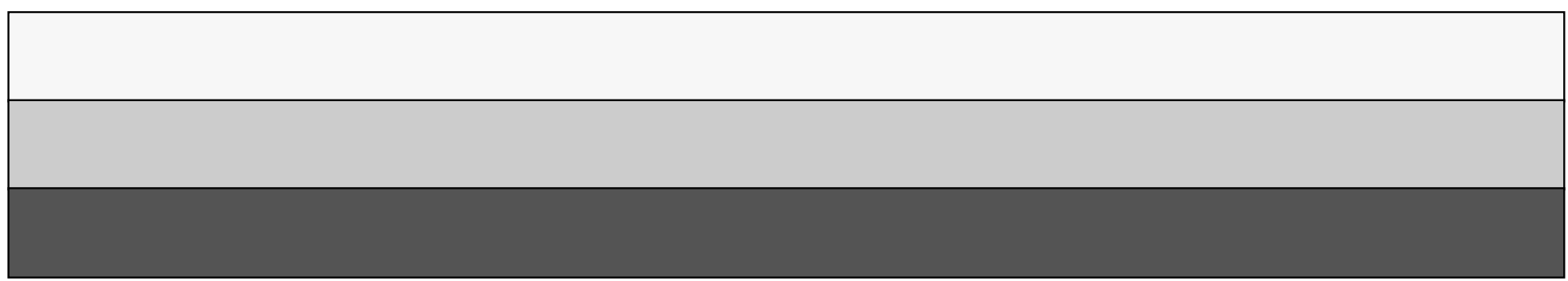

